\title{
Tinnitus, Enophthalmos, And Transient Thrombocytopenia As Symptoms Of Metastatic Breast Cancer Without Local Disease
}

\author{
Gianni D’Egidio H.BSc, M.D., M.Eng; Kwadwo Kyeremanteng MD MHA
}

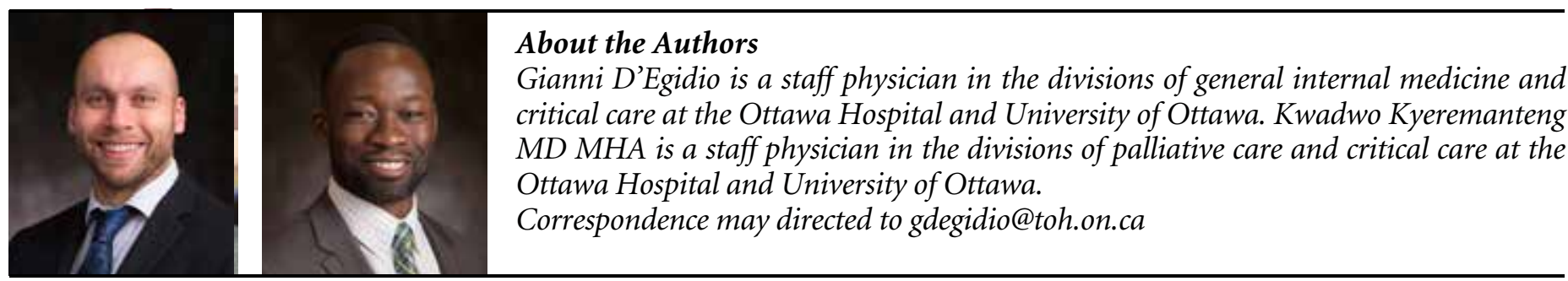

\section{Summary}

A 57 year old woman with a past medical history of oculopharyngeal muscular dystrophy presents with tinnitus, thrombocytopenia, and enophthalmos. She then develops subcutaneous skin nodules on her abdomen. Initial biopsies of the cutaneous nodules revealed adenocarcinoma of unknown origin. CT imaging of her chest, abdomen, and pelvis reveal atypical peritoneal carcinomatosis and possible diffuse bone marrow infiltration. CA -125, CEA and CA-19 are negative. Upper and lower endoscopies are normal along with bilateral mammograms of the breast. Repeat biopsy of the skin nodules and bone marrow biopsy reveals lobular carcinoma of the breast. She is treated with hormone modifying therapy for approximately one year but subsequently passes away.

\section{Résumé}

Une femme de 57 ans avec des antécédents médicaux de dystrophie musculaire oculopharyngée présente un acouphène, une thrombopénie et une énophtalmie. Puis, elle développe des nodosités sous-cutanées à l'abdomen. Les premières biopsies de ces nodules révèlent la présence d'un adénocarcinome d'origine inconnue. L'imagerie par tomodensitométrie du thorax, de l'abdomen et du bassin révèle une carcinomatose péritonéale atypique et une possible infiltration diffuse de la moelle osseuse. Les dosages du CA 125, de l'ACE et du CA 19-9 sont négatifs. Les endoscopies haute et basse sont normales, tout comme les mammographies des seins. De nouvelles biopsies des nodosités cutanées et une biopsie de la moelle osseuse révèlent la présence d'un carcinome lobulaire du sein. La patiente suit un traitement d'hormonothérapie durant environ un an, mais elle décède ultérieurement.

\section{Key Points}

1. Enopthalmosis can be a presenting symptom of sclerosing metastatic breast cancer.

2. Tinnitus can be a paraneoplastic phenomenon.

3. Malignancies can be widely metastatic without obvious local disease.

4. The diagnostic evaluation of a patient with cancer of an unknown primary requires targeted investigations based on the individual patient and usually requires multidisciplinary approach.

\section{Case presentation}

A previously healthy 57-year-old female on no medications with a family history (mother) of oculopharyngeal muscular dysplasia (OPMD) initially develops severe tinnitus after a transatlantic flight in 2009. While not as severe as the initial episode, she continues to suffer from tinnitus. In 2010, she begins to notice worsening ptosis and dysphagia. Given her strong family history, she seeks consultation from a neurologist and formal genetic testing reveals abnormal triplet repeats in the PABPN1 gene in chromosome 14 confirming 
the diagnosis of OPMD. CT head in 2011 is normal. Isolated thrombocytopenia on routine bloodwork is also discovered by her family physician in late 2010. In the summer of 2012, she notices that her eyes were "sinking in" and is seen by an ophthalmologist who confirms the diagnosis of enophthalmos.

In the spring of 2013, she begins to notice subcutaneous nodules appearing on her abdomen. Subsequent punch biopsy of skin in April of 2013 are consistent with adenocarcinoma of unknown primary (Table 1 Column 2). She then undergoes a full work up in an effort to determine the primary source. CT scans of the neck and chest are normal. CT of the abdomen and pelvis reveals an unusually diffuse infiltrative process with minimal or no ascites consisting of soft tissue infiltrating the root of the mesentery, retroperitoneum pelvic sidewall and over the surface of the bowel. There is also splenomegaly and marked diffuse sclerosis of the bones suggesting either lymphoma or myelofibrosis.

Her bloodwork from April 2013 is shown in Table 2. She has now developed anemia and lymphocytosis in addition to her thrombocytopenia. Nucleated RBCs are also present. Her tumor markers are negative (Table 2 Column 3). She has minimally elevated liver enzymes and her serum protein electrophoresis is normal. Upper and lower endoscopies are normal along with bilateral mammography.

She is evaluated by a medical oncologist who suggests a repeat of the skin biopsy and bone marrow biopsy given the lack of a clear source of her malignancy. After immunohistochemical stains are completed on the skin biopsy, it is determined she has morphologic and immunohistochemical features (ER+ GATA+) most consistent with a metastatic adenocarcinoma that favors infiltrating lobular carcinoma of mammary origin (Table 1).

Interestingly, repeat blood work in June 2013 reveals her thrombocytopenia has resolved but her anemia and lymphocytosis persists (Table 2 Column 4). She undergoes bone marrow aspirate and biopsy which reveals extensive infiltration by metastatic adenocarcinoma with fibrosis and osteosclerosis. There is no evidence of lymphoma and stains were consistent with the skin biopsy performed earlier.

She is seen by a breast oncologist who starts her on an aromatase inhibitor, anastrazole, in August of 2013. Over the next few months her tinnitus remains the same but her enophthalmos worsens. She undergoes CT head in October 2013 which reveals severe bilateral enophthalmos with an infiltrative process in the retro-orbital tissue, which is confirmed by an MRI with gadolinium in November of 2013 (Figure 1).

She eventually develops hypercalcemia of malignancy in March 2014 and receives zoledronic acid. She develops increasing fatigue, worsening enophthalmos and ptosis in the summer of 2014 along with episodes of delirium. She passes away in June 2014 after electing to pursue a purely palliative approach.

\section{Discussion}

\section{Cancer of unknown primary (CUP)}

Adenocarcinomas of unknown primary site comprise approximately 70 percent of CUPs. ${ }^{1}$ Our diagnostic approach was a thorough history and physical examination, routine bloodwork with CT of the chest, abdomen, and pelvis.

We included mammography, which was negative. Mammography is a commonly performed investigation in females with CUP, but its value has not been clearly established. ${ }^{2}$ The small number of published studies of mammography in females with CUP suggests that mammography has limited value. ${ }^{2}$ However, a diagnosis of breast cancer has "high value" as these patients often respond to targeted therapies and have a better outcome than other CUP groups, therefore, mammography should be performed if initial histology or cytology suggests a possible breast cancer. ${ }^{2}$

MRI may be indicated with a negative mammography as MRI may better detect certain breast cancers like lobular carcinomas. MRI has been shown, across a number of small series, to have a high sensitivity for detection of occult breast primary. ${ }^{2}$

In a male patient, we would have included prostate examination and measurement of serum prostate specific antigen (PSA). We also included both upper and lower endoscopies (both unremarkable) as the $\mathrm{CT}$ abdomen revealed involvement of the mesentery and large bowel which was suggestive of a GI source.

As a result of negative imaging and no clear source, we elected to investigate tumor markers CA 19-9, CA 125, and CEA. All were negative. Some have suggested that CUP have a nonspecific over-expression of the above serum tumor markers and that routine use of these markers does not offer any diagnostic or prognostic assistance. ${ }^{3}$

Given the negative investigations, the oncologic team suggested a repeat biopsy and immunohistochemical (IHC) staining. The histologic findings of both biopsies were similar; however, the second biopsy specimen was positive for GATA and ER (Table 1). Given the discrepant findings of the two biopsy specimens, repeat GATA, ER, and PR stains were performed on the first specimen. The repeated stains were still negative for GATA, ER, and PR. The external positive controls were deemed appropriate and it was thought that the discrepant results were due to heterogeneity within the tumor cells.

We suggest that, after a thorough investigation has been completed and there is no clear primary source, repeat biopsy 


\begin{tabular}{|c|c|c|}
\hline $\begin{array}{l}\text { Immunohistochemical } \\
\text { stains and molecular } \\
\text { markers }\end{array}$ & $\begin{array}{l}\text { Punch } \\
\text { biopsy of } \\
\text { subcutaneous } \\
\text { nodule April } \\
2013\end{array}$ & $\begin{array}{l}\text { Punch } \\
\text { biopsy of } \\
\text { subcutaneous } \\
\text { nodule June } \\
2013\end{array}$ \\
\hline $\mathrm{AE} 1 / 3$ & + & + \\
\hline CK7 & + & + \\
\hline CD45 & - & - \\
\hline $\mathrm{S} 100$ & - & - \\
\hline Cytokeratin 20 & - & - \\
\hline ER & - & + \\
\hline PR & - & - \\
\hline GATA & - & + \\
\hline $\mathrm{S} 100$ & - & - \\
\hline $\mathrm{CDX} 2$ & - & - \\
\hline TTF-1 & - & - \\
\hline p40 & - & - \\
\hline CK5 & - & - \\
\hline Synaptophysin & - & - \\
\hline CD3 & - & - \\
\hline CD20 & - & - \\
\hline Mucicarmine & Non-contributory & + \\
\hline PAX8 & - & - \\
\hline HER-2/neu & Not done & - \\
\hline
\end{tabular}

Table 1. Immunohistochemical and molecular marker results of skin biopsy specimens
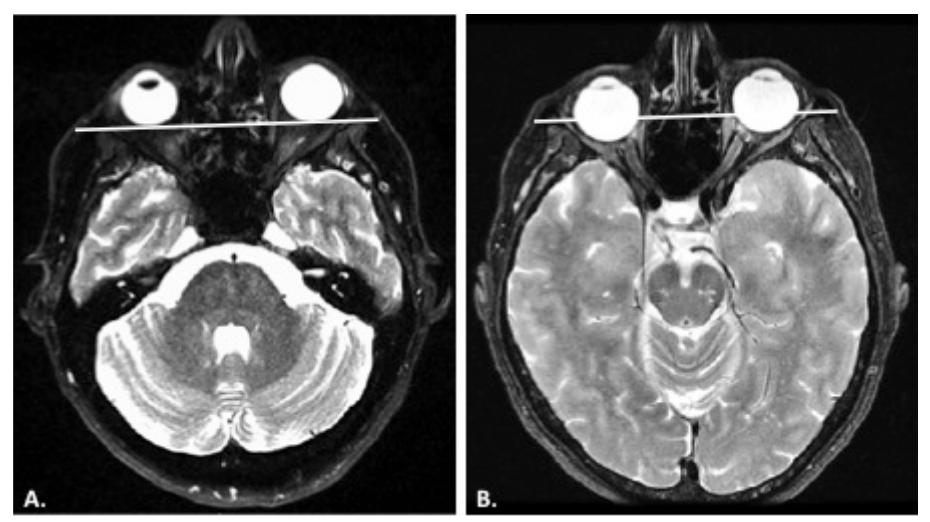

Figure 1 - Axial T2 weighted Turbo/Fast Spin Echo images obtained in 2011 (A) and 2015 (B) demonstrate progressive enophthalmos. In (A) the posterior margin of the globes are touching a horizontal line (white line) drawn across the zygomatic arches (interzygomatic line). In (B), the posterior margin of the globes are now posterior to the interzygomatic line, findings compatible with enophthalmos. may be considered in select situations taking into account the risks of the proposed biopsy site. In our case, biopsy of the skin carried a very low risk of side effects. Obviously the risk would increase with vital areas such as lung or intra-abdominal sites. In women with CUP and peritoneal carcinomatosis, imageguided biopsy with histology and IHC was diagnostic in 93\% of cases, with repeat biopsy required in $7 \%$ of cases. ${ }^{4}$

\section{Tinnitus}

Tinnitus is a common disorder, approaching $12 \%$ prevalence in men the ages of $65-74$, that has no proven therapies. ${ }^{5}$ It can be divided into subjective and objective tinnitus (Table 3). Objective tinnitus is defined as patients who are hearing real sounds whereas subjective tinnitus is a false perception of sound (there is no acoustic stimulus). ${ }^{5}$ The approach to a patient complaining of tinnitus should be a complete history, physical exam focusing on the head, neck, oral cavity, outer ear, tympanic membrane, cranial nerves, and temporomandibular joint and cardiovascular exam. Neuroimaging should be performed if there is no obvious cause on exam and, because of the association with hearing loss, an audiologic exam should be ordered. Lockwood et al. provide an excellent approach to patients with tinnitus (Figure 2). ${ }^{5}$

Tinnitus may also be the result of a paraneoplastic phenomenon.There are many case reports of tinnitus associated with malignancies such as atrial myxoma, Hodgkin's and paraneoplastic antibodies ${ }^{6-8}$ with no direct involvement of the auditory apparatus. In the case of this patient, we suspect the tinnitus was related to her breast cancer and was likely a paraneoplastic phenomenon given the multiple normal CT and MRIs of her brain. A very rudimentary search of pub med and google scholar did not reveal any case reports of tinnitus associated with metastatic breast cancer without local involvement.

\section{Enophthalmos}

Enophthalmos can be the result of a variety of etiologies (Table 4). ${ }^{9}$ Metastatic spread of cancer to the orbit is rare and accounts for minority of cases. ${ }^{10}$ Fibrosing breast cancer is the most common cancer that metastasizes to the orbit and is thought to cause enophthalmos by inducing retraction of the orbital contents. ${ }^{10}$ We suspect the cause of the patient's enophthalmos was the metastatic breast cancer and not her previous diagnosis of OPMD. Our patient had diffuse fibrotic involvement of her bone marrow and infiltration of her orbits based on MRI imaging. OPMD is characterized by bilateral ptosis, dysphagia and skeletal muscle weakness; we could not find any link between OPMD and enophthalmos. 


\begin{tabular}{|l|c|c|c|c|}
\hline Laboratory test & Value & Value & Value & Normal range \\
\hline White blood cell & April 2013 & & June 2013 & \\
\hline Hemoglobin & 8.9 & & 12.1 & $3.5-10.5 \times 10^{9} / \mathrm{L}$ \\
\hline Mean Corpuscular Volume & 98.4 & & 96.9 & $80-100 \mathrm{fL}$ \\
\hline Platelets & 67 & & 135 & $130-380 \times 10^{9} / \mathrm{L}$ \\
\hline Lymphocytes & 4.54 & & 7.8 & $0.8-3.3 \times 10^{9} / \mathrm{L}$ \\
\hline Basophils & 0.27 & & 0.1 & $0-0.1 \times 10^{9} / \mathrm{L}$ \\
\hline Nucleated Red Blood Cells & 5 & & 0 & 0 \\
\hline Bilirubin & 17 & & 16 & umol/L \\
\hline AST & 62 & & 65 & U/L \\
\hline ALT & 71 & & 64 & U/L \\
\hline GGT & 66 & & NP & U/L \\
\hline LD & 381 & & NP & U/L \\
\hline CA 19-9 & & 1 & & $<35 \mathrm{kU} / \mathrm{L}$ \\
\hline CA-125 & & 34 & & $0-35 \mathrm{kU} / \mathrm{L}$ \\
\hline CEA & & 1.2 & & $<3.0 \mathrm{ug} / \mathrm{L}$ \\
\hline
\end{tabular}

Table 2. Laboratory values

\begin{tabular}{|l|l|}
\hline Subjective tinnitus & \\
\hline Otologic & $\begin{array}{l}\text { Noise induced hearing loss, presbycusis, otosclerosis, otitis, impacted } \\
\text { cerumen,sudden deafness, Meniere's disease, and other causes of hearing } \\
\text { loss }\end{array}$ \\
\hline Neurologic & $\begin{array}{l}\text { Head injury, whiplash, multiple sclerosis, vestibular schwannoma } \\
\text { (commonly called an acoustic neuroma) or other cerebellar-pontine-angle } \\
\text { tumors }\end{array}$ \\
\hline Infectious & $\begin{array}{l}\text { Otitis media and sequelae of Lyme disease, meningitis, syphilis, and other } \\
\text { infectious or inflammatory processes that affect hearing }\end{array}$ \\
\hline Drug related & $\begin{array}{l}\text { Common side effect of many drugs, such as salicylates, nonsteroidal } \\
\text { antiinflammatory } \\
\text { drugs, aminoglycoside antibiotics, loop diuretics, and chemotherapy } \\
\text { agents (e.g., platins and vincristine) }\end{array}$ \\
\hline Other & Temporomandibular-joint dysfunction and other dental disorders \\
\hline
\end{tabular}

\begin{tabular}{|l|l|}
\hline Objective tinnitus & \\
\hline Pulsatile & $\begin{array}{l}\text { Carotid stenosis, arteriovenous malformations, other vascular anomalies, } \\
\text { vascular tumors (e.g., of the glomus jugulare), valvular heart disease } \\
\text { (usually aortic stenosis), states of high cardiac output (anemia and drug } \\
\text { induced high output), and other conditions causing turbulent blood flow }\end{array}$ \\
\hline Muscular or anatomical & $\begin{array}{l}\text { Palatal myoclonus, spasm of stapedius or tensor tympani muscle, patulous } \\
\text { eustachian tube }\end{array}$ \\
\hline Spontaneous & Spontaneous otoacoustic emissions \\
\hline
\end{tabular}

Table 3. Causes of tinnitus 


\section{Symptoms of Metastatic Breast Cancer Without Local Disease}

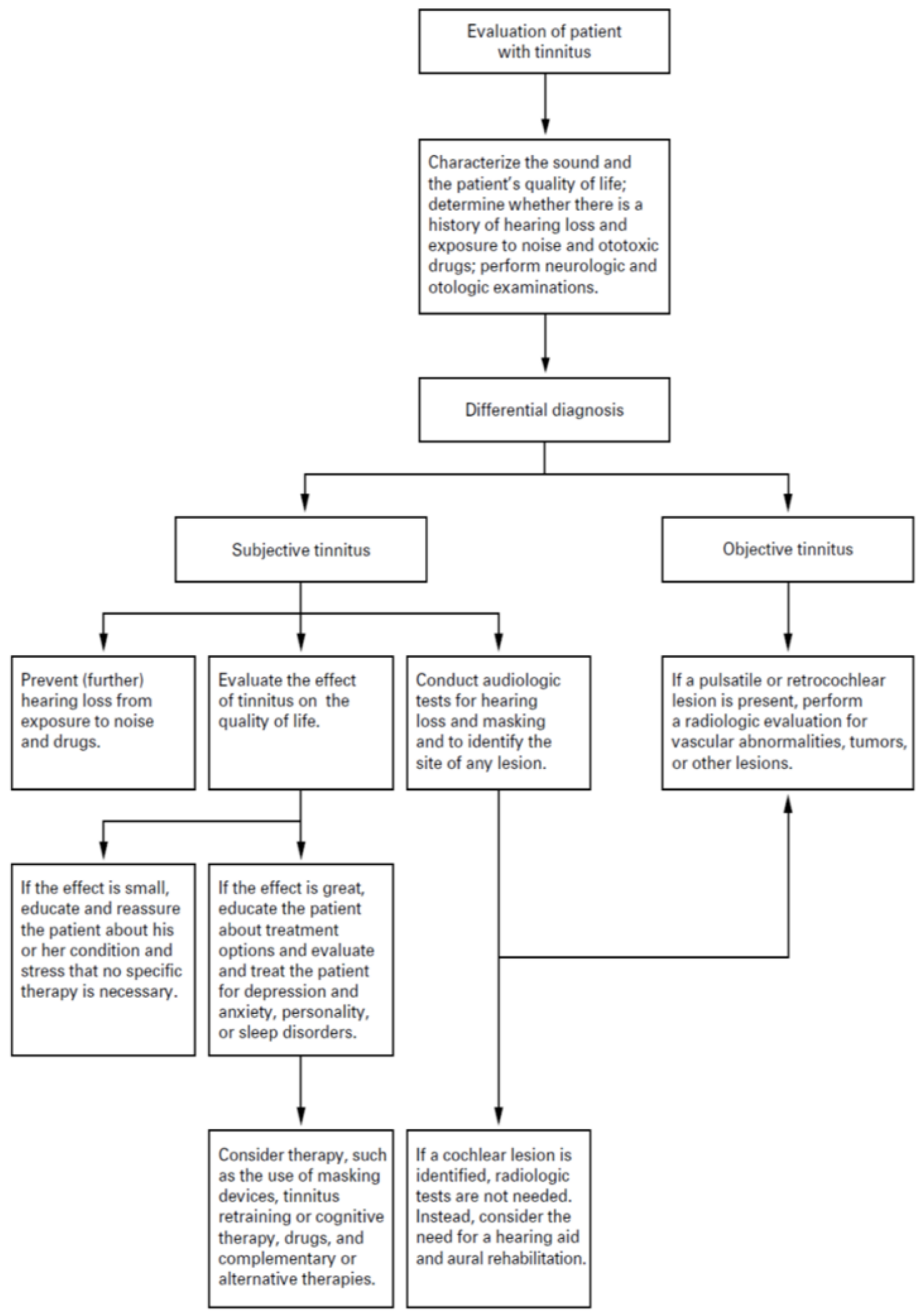

Figure 2. Diagnostic algorithm for a patient with tinnitus. 


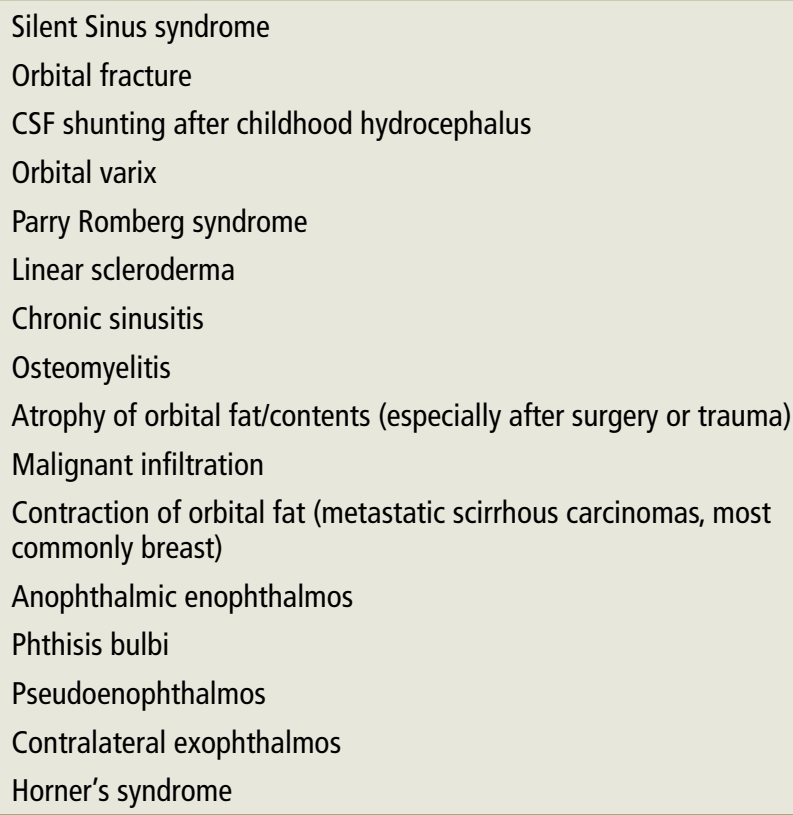

Table 4. Differential Diagnoses of Enophthalmos

\section{Thrombocytopenia}

Thrombocytopenia can be caused by destruction, sequestration, or decreased production of platelets. Bone marrow infiltration by hematologic or solid malignancies is a cause of thrombocytopenia. Interestingly, our patient had a 3-year history of only thrombocytopenia and no other hematologic abnormalities, which we believe is as a result of her undiagnosed malignancy. It was not until she presented with the subcutaneous skin nodules that testing showed she had developed anemia and lymphocytosis. Also, her platelet count normalized before receiving therapy in June of 2013 (Table 2 column 4) and the remainder of her hematologic abnormalities resolved in concordance with her therapy.

\section{References}

1. Hainsworth JD and Greco FA. Adenocarcinoma of unknown primary site. In: UpToDate, Canellos GP and Ross ME (Ed), UpToDate, Waltham, MA. (Accessed on March 11, 2015)

2. Taylor MB, Bromham NR, and Arnold SE. Carcinoma of unknown primary: key radiological issues from the recent National Institute for Health and Clinical Excellence guidelines. Br J Radiol. 2012 Jun; 85(1014): 661-671

3. Pavlidis N, Kalef-Ezra J, Briassoulis E, Skarlos D, et al. Evaluation of six tumor markers in patients with carcinoma of unknown primary. Med Pediatr Oncol. 1994;22(3):162.

4. Hewitt MJ, Hall GD, Wilkinson N, Perren TJ, Lane G, Spencer JA. Imageguided biopsy in women with breast cancer presenting with peritoneal carcinomatosis. Int J Gynecol Cancer 2006;16:108-10.

5. Lockwood AH, Salvi RJ, Burkard RF. Tinnitus. N Engl J Med. 2002 Sep 19;347(12):904-10.

6. Smith MJ1, Chaudhry MA, Humphrey MB, Lozano PM. Atrial myxoma and bone changes: a paraneoplastic syndrome? J Card Surg. 2011 Jul;26(4):375-7.

7. Peltola J, Hietaharju A, Rantala I, Lehtinen T, et al. A reversible neuronal antibody (anti-Tr) associated paraneoplastic cerebellar degeneration in Hodgkin's disease. Acta Neurol Scand 1998: 96: 360-363.

8. Pittock SJ1, Lucchinetti CF, and Lennon VA. Anti-neuronal nuclear autoantibody type 2: Paraneoplastic accompaniment. Ann Neurol. 2003 May;53(5):580-7

9. Hong ES, Allen RC. Silent Sinus Syndrome: 36-year-old male with sunken left orbit (Enophthalmos). EyeRounds.org. January 4, 2010; Available from: http://www.EyeRounds.org/cases/102-Enophthalmos-Silent-Sinus-Syn.htm. (Accessed on March 10, 2015)

10. Novitskaya E, Rene C. Enophthalmos as a sign of metastatic breast carcinoma. CMAJ. 2013 Sep 17;185(13):1159 